\title{
Childhood Inattention and Dysphoria and Adult Obesity Associated with the Dopamine D4 receptor Gene in Overeating Women with Seasonal Affective Disorder
}

\author{
RD Levitan*,', M Masellis², RW Lam³, P Muglia ${ }^{2}$, VS Basile², U Jain', AS Kaplan ${ }^{4}$, S Tharmalingam², \\ SH Kennedy ${ }^{4}$ and JL Kennedy ${ }^{2}$ \\ 'Department of Psychiatry, Centre for Addiction and Mental Health, University of Toronto, Canada; ${ }^{2}$ Department of Psychiatry, Neurogenetics \\ Section, Centre for Addiction and Mental Health, University of Toronto, Canada; ${ }^{3}$ Department of Psychiatry, University of British Columbia, \\ Canada; ${ }^{4}$ Department of Psychiatry, Toronto General Hospital, University Health Network, University of Toronto, Canada
}

\begin{abstract}
There is significant evidence that altered dopamine activity plays a role in seasonal affective disorder (SAD). The current study examined three separate genetic hypotheses for SAD related to the 7-repeat allele (7R) of the dopamine-4 receptor gene (DRD4), a variant associated with decreased affinity for dopamine. We examined the possible contribution of 7R to the overall expression of SAD, attention deficit disorder (ADD) comorbidity, and body weight regulation. As part of an ongoing genetic study of increased eating behavior and mood in female subjects, 108 women with winter SAD and carbohydrate craving/weight gain were administered the Wender-Utah Rating Scale to measure childhood ADD symptomatology, and a questionnaire to assess maximal lifetime body mass index (BMI). To test for an association between 7R and the categorical diagnosis of SAD, the transmission disequilibrium test (TDT) was used in a subsample of probands providing familial DNA. Standard parametric tests were used to compare childhood ADD symptoms and maximal lifetime BMI across the two genotypic groups defined by the presence or absence of 7R. The TDT found no initial evidence for an association between 7R and the categorical diagnosis of SAD. However, 7R carriers reported significantly greater inattention and dysphoria in childhood $(p=0.01$ and $0.00 \mathrm{I}$, respectively) and a higher maximal lifetime BMI $(p=0.007)$ than did probands without this allele. Furthermore, excluding probands with extreme obesity (maximal BMI > 40), a strong correlation was found linking childhood inattentive symptoms and maximal lifetime BMI $(r=0.35, p=0.00 \mathrm{I})$. In overeating women with SAD, the 7R allele of DRD4 may be associated with a unique developmental trajectory characterized by attentional deficits and dysphoria in childhood and mild to moderate obesity in adulthood. This developmental course may reflect different manifestations of the same underlying vulnerability related to central dopamine dysfunction. Given the possibility of population stratification when studying genotype/phenotype relationships, future use of genomic controls and replication of our findings in other overeating and/or ADD populations are needed to confirm these initial results.
\end{abstract}

Neuropsychopharmacology (2004) 29, I79-186, advance online publication, I5 October 2003; doi: I0.1038/sj.npp. I3003।4

Keywords: seasonal affective disorder; attention deficit disorder; obesity; dopamine 4 receptor gene

\section{INTRODUCTION}

Winter seasonal affective disorder (SAD) is a subtype of depression characterized by a predictable onset in the fall/ winter period and spontaneous remission in the spring and summer months (Rosenthal et al, 1984). There is considerable evidence for genetic contributions to SAD (Madden et al, 1996; Sher, 2001), and several candidate gene studies

\footnotetext{
*Correspondence: Dr R Levitan, c/o Clarke Division of CAMH, 250 College Street, I Ith floor, Toronto, Ontario, Canada M5T IR8, Tel: + I 416535850 I ext. 4020, Fax: + I 416979682 I,

E-mail: robert_levitan@camh.net

Received 16 May 2003; revised 25 July 2003; accepted 19 August 2003 Online publication: 26 August 2003 at http://www.acnp.org/citations/ Npp082603032/8/default.pdf
}

of SAD have been reported (Ozaki et al, 1996; Rosenthal et al, 1998; Enoch et al, 1999; Johansson et al, 2001; Arias et al, 2001; Praschak-Rieder et al, 2002; Johansson et al, 2003). Based on strong evidence for serotonin dysfunction in SAD (Lam et al, 1996; Schwartz et al, 1997; Levitan et al, 1998), the vast majority of these studies have focused on serotonin system genes, with inconclusive results. Despite significant evidence that altered dopamine activity also plays an important role in SAD (Depue et al, 1990; Arbisi et al, 1994; Neumeister et al, 2001; Lam et al, 2001), no candidate gene studies based on the dopamine system have been reported in SAD probands to date. The goal of the current study was to explore three separate genetic hypotheses for SAD related to the dopamine-4 receptor gene (DRD4). DRD4 is an excellent candidate for genetic 
association studies as it displays a high degree of variability, and a functional variable number of tandem repeat (VNTR) polymorphism has been identified in the third exon, the region coding for the third intracellular loop of the receptor (Van Tol et al, 1992). In vitro studies suggest that the exon III DRD4 7-repeat allele (7R) has decreased affinity for dopamine and transmits weaker intracellular signals in comparison to other exon III alleles (Asghari et al, 1995).

The first hypothesis we considered was that variation in DRD4 might contribute to the overall categorical diagnosis of SAD. However, given the dimensional and heterogenous nature of $\mathrm{SAD}$, we also examined whether variation in DRD4 might account for individual differences in symptom presentation among SAD probands. For example, clinically we have found that many women with SAD report a childhood history of attention deficit disorder (ADD), a pattern of comorbidity that has previously been described in both children (Rosenthal, 1995) and in adults presenting with long-standing ADD symptoms (Levitan et al, 1999). Neuroimaging studies also support an overlap between adult $\mathrm{ADD}$ and $\mathrm{SAD}$, with both disorders exhibiting decreased global metabolism and marked hypoactivity in prefrontal areas mediating attentional control (Zametkin et al, 1990; Cohen et al, 1992). DRD4 is of particular interest in this regard in that DRD4 receptors are highly expressed in the prefrontal cortex (Mrzljak et al, 1996), and numerous studies have demonstrated a significant association between the 7R allele of DRD4 and ADD (LaHoste et al, 1996; Rowe et al, 1998, 2001; Smalley et al, 1998, 2001; Swanson et al, 1998; Faraone et al, 1999; Barr et al, 2000; Holmes et al, 2000; Muglia et al, 2000; Tahir et al, 2000; Mill et al, 2001; Curran et al, 2001). Based on these various lines of research, it was hypothesized that in a larger group of women with $\mathrm{SAD}$, the $7 \mathrm{R}$ allele of DRD4 might be associated with childhood ADD symptoms.

The third hypothesis for the current study was that variation in DRD4 might contribute to increased body mass in SAD. The typical patient with SAD is a premenopausal female with marked craving for high-carbohydrate/high-fat foods, resulting in significant weight gain during winter depressive episodes (Rosenthal et al, 1987). Individuals with SAD consume such foods to modify negative mood states (Krauchi et al, 1997), suggesting that brain reward pathways may be involved. Dopamine activity in the meso-corticolimbic circuitry of the brain has been shown to mediate the rewarding properties of foods (Hernandez and Hoebel, 1990; Evans and Vaccarino, 1990; Martel and Fantino, 1996), while treatment with the dopamine antagonist clozapine, which has high affinity for the D4 receptor (Seeman and Van Tol, 1994), is frequently complicated by increased food consumption and weight gain (Theisen et al, 2003). As D4 receptors are expressed in various brain regions that comprise the natural reward pathway (MeadorWoodruff et al, 1996; Civelli, 1995), variation in DRD4 might be expected to contribute to individual differences in eating behavior and thus weight gain.

To summarize, the specific hypotheses for the current study were that in overeating women with SAD, the 7R allele of DRD4 might be associated with (1) the overall diagnosis of SAD and/or (2) childhood symptoms of ADD, and/or (3) higher maximal lifetime body mass. We report here our preliminary findings in 108 women presenting with winter SAD and increased appetitive behavior.

\section{METHOD}

\section{Sample}

The current study group consisted of female paticipants 2065 years of age, who met DSM-IV criteria for major depression with a winter seasonal pattern, recruited at the mood disorder clinics of both the Centre for Addiction and Mental Health in Toronto, and the University of British Columbia in Vancouver. As our ongoing genetic study has a particular focus on women who overeat, only female subjects who experienced carbohydrate craving and/or weight gain during their winter depressive episodes were included. Increased appetitive behavior occurs in over $70 \%$ of SAD patients, is particularly common in females, and is highly sensitive to bright light therapy (Krauchi et al, 1993), making it a core phenotype for SAD. To be entered into the current study, women had to report increased eating and/or weight gain during winter depressive episodes, based on their clinical consultation interview carried out by one of us (RDL or RWL), and on a revised version of the Hamilton Depression Rating Scale specifically developed for SAD (SIGH-SAD) (Williams et al, 1988), which includes several 'atypical' items. Study candidates had to score 3 or greater based on the sum of scores across the four items, which assess increased appetitive behavior and weight. The SIGH-SAD was administered by a trained research assistant.

Each subject was given an oral and written summary of the purposes, procedures, and potential risks of the project and gave informed written consent. The protocol was approved by the University of Toronto and UBC research ethics committees.

\section{Rating Scales}

The Wender-Utah Rating Scale (WURS). The WURS is a self-report rating scale given to adults to assess retrospectively symptoms of childhood ADD (Ward et al, 1993). All items are rated 0 (not at all or very slightly) to 4 (very much). There are 61 items in total, including 42 that describe various aspects of childhood behavior, seven for medical problems, and 12 items related to school performance, reading, and writing. A 25-item subscale has also been derived to best differentiate core ADD symptoms from those of major depression (Ward et al, 1993). This WURS25 subscale is ideal for use in depressed adults as it minimizes the confounding effects of depression on the retrospective reporting of childhood ADD symptoms.

A factor analysis to evaluate potential gender differences on the WURS revealed a 5-factor solution for female patients, which included factors for (1) dysphoria; (2) impulsivity and problems with conduct; (3) inattention and organizational problems; (4) problems with learning; and (5) unpopularity (Stein et al, 1995).

The SIGH-SAD. As alluded to above, the SIGH-SAD is a revised version of the Hamilton Depression Rating Scale specifically designed to measure the 'atypical' neurovegeta- 
tive symptoms of SAD, such as overeating, weight gain, and hypersomnia (Williams et al, 1988). The SIGH-SAD provided a state measure of depression and was administered by a trained research assistant.

Assessment of maximal lifetime body mass. As part of the structured interviewing carried out by a research assistant, each proband was administered a brief questionnaire, which included a question about maximum weight achieved as an adult with corresponding height. The maximum lifetime body mass index (BMI) was calculated for each subject using the formula (weight in kilograms/(corresponding height in meters $\left.{ }^{2}\right)$ ).

\section{Procedure}

All subjects were given a clinical diagnosis of winter SAD by one of two psychiatrists expert in this field (RDL, RWL). Upon meeting with a trained research assistant, subjects were asked to complete the WURS on their own. The research assistant then administered the Structured Clinical Interview for DSM-IV-patient edition (SCID-P) (First et al, 2002) and the SIGH-SAD. Blood samples for DNA extraction were also collected at this time. All subjects were asked to provide consent, which allowed us to contact parents and siblings to obtain blood samples for DNA. Where possible, family-based units including (a) one or both parents, (b) one parent and one or more sibs, or (c) two or more sibs were asked to provide blood for DNA for a family-based control transmission disequilibrium analysis.

\section{Laboratory Methods}

Blood samples were collected from the clinical sites and sent to the Clarke Division, Centre for Addiction and Mental Health. Genomic DNA was extracted from white blood cells using the high-salt method. All genotyping of the DNA was performed blind to psychiatric diagnosis and vice versa. This was facilitated through a standard patient identification coding system employed by our laboratory. The 48 base pair VNTR region in the third exon of DRD4 was amplified using polymerase chain reaction techniques with primers and conditions previously published (Lichter et al, 1993). The PCR products were visualized via gel electrophoresis performed in $3.5 \%$ agarose prepared with ethidium bromide and $1 \times$ TBE (Tris, boric acid, EDTA).

\section{Statistical Methods}

Hypothesis 1. To test the hypothesis that the $7 \mathrm{R}$ allele of DRD4 is associated with the overall categorical diagnosis of $\mathrm{SAD}$, while limiting the problem of population stratification, the transmission disequilibrium test was performed on the subgroup of probands with familial controls available. This was performed using the Family-Based Association Test (FBAT v1.2), which counts the alleles transmitted to the affected offspring $v s$ those not transmitted as deduced from the parental genotypes. While we hope to implement genomic controls for probands without familial DNA in the future, funding for this was not available at the time of this report.
Hypotheses 2 and 3. As these hypotheses were based on continuous rather than categorical measures, a quantitative statistical approach was used for these analyses. Each proband was grouped according to the presence or absence of the $7 \mathrm{R}$ allele. ADD rating scale scores and maximum lifetime BMI measures were then compared across $7 \mathrm{R}$ carriers and noncarriers using unpaired $t$-tests.

Based on the specific and unidirectional nature of the main working hypotheses, a significance level of 0.05 was chosen for our primary analyses. For subscale analyses, to correct for multiple comparisons, a $p$-level of 0.01 was used.

\section{RESULTS}

A total of 108 women with SAD, with a mean age of $37.8 \pm 9.4$ years, were included in this study. The DRD4 VNTR exon 3 polymorphism was in Hardy-Weinberg equilibrium.

Hypothesis 1. The $7 R$ allele of DRD4 will be associated with the overall categorical diagnosis of $S A D$. The number of probands having informative family-based data for the FBAT analysis was 45 . No association is currently being detected between the $7 \mathrm{R}$ allele and the categorical diagnosis of SAD (observed 7R alleles in SAD probands $=24$, expected $7 \mathrm{R}$ alleles based on parental genotypes $=24.2, Z=0.07$, $p=0.90)$. These preliminary results suggest that the number of 7R transmissions to probands with SAD does not deviate from the null hypothesis, although the statistical power to detect a significant difference was only 0.3 in this small sample.

Hypothesis 2. In probands with $S A D$, the $7 R$ allele will be associated with childhood ADD symptomatology. Mean WURS scores for the full sample of $108 \mathrm{SAD}$ probands were: total 61-item WURS: $64.3 \pm 28.5$; core 25 -item WURS: $30.4 \pm 18.7$. A comparison of childhood ADD scores across the two genotypic groups defined by the presence or absence of the $7 \mathrm{R}$ allele is included in Table 1. In total, 37 (34\%) of subjects carried at least one version of the $7 \mathrm{R}$ allele. As hypothesized, 7R carriers scored significantly higher on the WURS-25, which measures core symptoms of ADD during childhood. Key subscales based on a large factor analysis of female subjects with ADD (Stein et al, 1995) were also compared across the two groups. The results indicated that $7 \mathrm{R}$ carriers had significantly higher scores on the inattention and dysphoria factors, but did not differ on factors measuring impulsivity/conduct problems, learning problems, and unpopularity. The power for the $T$-statistic to detect genotypic group differences on the inattention subscale was 0.72 (95\% confidence interval (CI) for $T=0.75-5.85$ ), while for the dysphoria subscale it was 0.93 (95\% CI for $T=2.33-8.67$ ).

Hypothesis 3. In probands with $S A D$, the $7 R$ allele of DRD4 will be associated with higher maximal lifetime BMI. Maximal lifetime BMI data were available for 103 SAD probands, and are included in Table 1. Consistent with our working hypothesis, there was a significantly higher maximal lifetime BMI in probands carrying the $7 R$ allele. The power for the $T$-statistic to detect this difference was 0.80 (95\% CI for $T=1.11-6.29$ ). Using the well-established cutoff of a BMI $>30$ to define obesity, the lifetime rates of obesity in the two main genotypic groups were estimated at: 
Table I Age, Childhood ADD Scores, Maximal Lifetime Body Mass Indices and Current Depression Scores in Genotypic Groups Defined by the Presence or Absence of the 7-Repeat (7R) Allele of the DRD4 in 108 Overeating Women with SAD

\begin{tabular}{|c|c|c|c|c|c|}
\hline & $\begin{array}{l}\text { 7R carrier } \\
(\mathbf{N}=37)\end{array}$ & $\begin{array}{l}\text { 7R absent } \\
(\mathbf{N}=71)\end{array}$ & T-statistic & df & p-Value \\
\hline Age (years) & $36.6 \pm 9.6$ & $38.6 \pm 9.1$ & 0.25 & 102 & NS \\
\hline \multicolumn{6}{|l|}{ Wender-Utah childhood ADD scores } \\
\hline Total 61-item scale & $70.7 \pm 30.7$ & $61.0 \pm 26.9$ & 1.69 & 106 & 0.09 \\
\hline \multicolumn{6}{|l|}{ Subscale scores } \\
\hline Dysphoria & $14.0 \pm 8.8$ & $8.5 \pm 7.4$ & 3.46 & 106 & 0.001 \\
\hline Attentional problems & $7.6 \pm 6.5$ & $4.3 \pm 6.3$ & 2.61 & 106 & 0.01 \\
\hline Impulsivity and conduct problems & $8.3 \pm 6.4$ & $7.0 \pm 5.9$ & 1.04 & 106 & NS \\
\hline \multirow[t]{2}{*}{ Maximal lifetime body mass index } & $30.5 \pm 7.7$ & $26.8 \pm 5.5$ & 2.70 & 101 & 0.007 \\
\hline & $(\mathbf{N}=33)$ & $(\mathbf{N}=64)$ & & & \\
\hline \multicolumn{6}{|l|}{ Current depression scores } \\
\hline SIGH-SAD (25-item HDRS) & $24.4 \pm 9.7$ & $22.7 \pm 11.4$ & 0.72 & 93 & NS \\
\hline HDRS ( 17 -item) & $12.4 \pm 6.7$ & $10.9 \pm 6.7$ & 1.08 & 95 & NS \\
\hline
\end{tabular}

$\mathrm{N}=$ sample size; NS = nonsignificant; HDRS = Hamilton Depression Rating Scale; discrepancies in degrees of freedom are due to missing data.

7R present: 14/36 (38.9\%); 7R absent $13 / 67 \quad(19.4 \%)$ (Pearson $\chi^{2}=4.60 ; p=0.032$ ).

\section{Is There a Relationship Between Childhood ADD Symptoms and Adult Obesity in Female Probands with SAD?}

Based on these results, and two recent studies reporting very high rates of inattentive $\mathrm{ADD}$ in obese populations (Altfas, 2002; Fleming and Levy, 2002), we further explored a possible relationship between childhood ADD symptoms and maximal lifetime BMI in our SAD probands. No significant correlation was found between total WURS-61 scores and maximal lifetime BMI $(r=0.10, p=0.38$, $N=103$ ), although a trend was found linking maximal lifetime BMI with the inattentive subscale of the WURS $(r=0.18, p=0.067)$. Strikingly, when we excluded subjects with a history of extreme obesity as defined by the World Health Organization (ie maximal BMI above 40), based on the possibility that they are a genetically distinct subgroup (Clement et al, 1996; Li et al, 2000), a highly significant correlation was found linking childhood attentional problems with maximal lifetime BMI $(r=0.35, p=0.001$, $N=96$ ) (see Figure 1). In this same subgroup of nonmorbidly obese probands, childhood dysphoria was strongly correlated with both childhood attentional problems $(r=0.63, p=0.000, N=96)$ and maximal lifetime BMI $(r=0.32, p=0.002, N=96)$.

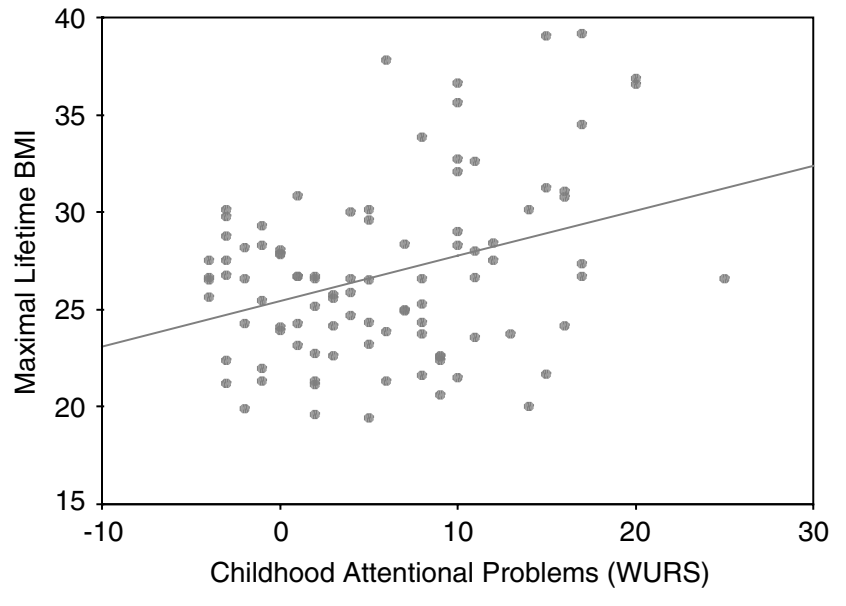

$$
r=0.35, p=0.001
$$

Figure I Scattergram plotting maximal lifetime BMI vs WURS attentional problems in childhood in overeating women with SAD (excluding individuals with maximal $\mathrm{BMI}>40$ ).

\section{DISCUSSION}

In a sample of women with $\mathrm{SAD}$ and increased appetitive behavior, we have found that the $7 R$ allele of the DRD4 exon III VNTR is associated with both inattention and dysphoria in childhood, and increased maximal lifetime BMI and 
obesity. These vulnerabilities may reflect different manifestations of the same underlying pathology related to central dopamine dysfunction. Preliminary data suggest that the $7 R$ allele is not strongly associated with the overall categorical diagnosis of SAD, although interpretation of the TDT data was limited by the small number of informative transmissions available. More work is needed to replicate these various findings, and to explore these associations in other populations, particularly those characterized by carbohydrate craving/weight gain and/or inattentive ADD.

The finding of an association between the $7 \mathrm{R}$ allele of DRD4 and childhood ADD symptoms confirms and extends numerous studies carried out in ADD probands (LaHoste et al, 1996; Rowe et al, 1998, 2001; Smalley et al, 1998; Swanson et al, 1998; Faraone et al, 1999; Barr et al, 2000; Holmes et al, 2000; Muglia et al, 2000; Tahir et al, 2000; Mill et al, 2001; Curran et al, 2001). In a recent meta-analysis of over 20 family-based and case-control studies, Faraone et al (2001) concluded that the 7R allele is highly likely to be a vulnerability factor for ADD. The fact that the 7-repeat allele was associated with inattention but not hyperactive/ impulsive behavior is also consistent with prior work. Twin studies in ADD have demonstrated independent heritability of these two key dimensions (Hudziak et al, 1998; Levy et al, 1997; Sherman et al, 1997). Furthermore, of the three DRD4 association studies that have looked at inattentive $v s$ hyperactive symptoms separately, two have shown a link with inattentive symptoms only (Rowe et al, 1998; McCracken et al, 2000) while a third was negative overall (Todd et al, 2001).

The current results also confirm and extend prior research linking central dopamine dysfunction with increased feeding behavior and obesity. Preclinical work suggests that dopamine plays a fundamental role in mediating the rewarding effects of food (Hernandez and Hoebel, 1990; Evans and Vaccarino, 1990; Martel and Fantino, 1996), consistent with its overall role in hedonics (Leshner and Koob, 1999). In humans, several lines of research suggest a key role for central dopamine activity in obesity, including pharmacological studies (Baptista, 1999; Halford, 2001), brain imaging work (Wang et al, 2001), and genetic studies (Comings et al, 1996; Noble, 2003). Given that the ease of availability of highly palatable foods in developed countries is a major factor contributing to the recent obesity epidemic (Macdiarmid et al, 1996; Blundell and Cooling, 1999), the identification of a genetic vulnerability factor that may play a role in food reward processes is of great interest. If replicated in other samples, the current results point to a genetic variant that could help in the early identification and treatment of female subjects at higher risk for certain forms of obesity due to abnormally increased food intake.

Also of interest in the current study was a possible relationship between childhood ADD symptoms, particularly inattention and dysphoria, and obesity in adulthood. Two prior studies carried out in medical obesity clinics have found very high rates of inattentive ADD symptoms, particularly in women (Altfas, 2002; Fleming and Levy, 2002). Both of these studies were initiated based on the clinical observation that poor treatment response for obesity appeared to be due to an inability to focus and organize meals. How might inattention and obesity be related mechanistically? Prior authors have suggested that poor planning and an inability to delay reward, processes largely mediated by the prefrontal cortex, may lead individuals with $\mathrm{ADD}$ to overconsume fattening foods (Fleming and Levy, 2002). A related hypothesis is that individuals with low intrinsic dopamine activity in brain areas mediating reward attempt to compensate by using various reinforcing behaviors including increased food consumption (Comings and Blum, 2000). This has been termed the 'reward deficiency syndrome' and has been described separately in ADD (Blum et al, 1995) and in obesity (Comings et al, 1996). Childhood ADD and adult obesity may thus reflect different manifestations of a single biological change related to the 7R allele of DRD4 and low dopamine activity in prefrontal attentional areas and brain reward pathways.

A number of limitations merit consideration. As this study was limited to female SAD patients who overeat, and given the current lack of a clear association between DRD4 and the overall diagnosis of $\mathrm{SAD}$, our findings may have more to do with the biology of weight regulation than with seasonality per se. To dissect out these relationships going forward, more studies of DRD4 and SAD are needed, as are studies of other overeating populations such as women with binge eating disorder and/or carbohydrate craving obesity. It will also be of great interest to study prospectively weight regulation in young female patients presenting with a primary diagnosis of inattentive ADD.

Our assessment of ADD symptoms was limited to a selfreport scale that does not on its own establish a clear diagnosis of ADD. Notwithstanding, our intention was not to study the categorical diagnosis 'ADD' but rather a dimension of psychopathology, tied to the dopamine system, that may be relevant to SAD probands. Regarding DRD4, while D4 receptors are expressed on prefrontal brain areas that mediate attention, and on meso-cortico-limbic structures that comprise the natural reward pathway (Meador-Woodruff et al, 1996; Civelli, 1995), relatively little is known about the physiological role of D4 in the human brain. While in theory, 7R might be associated with altered brain reward processes, this was not directly assessed in the current protocol, and other explanations for our BMI data in particular merit consideration. For example, the current findings might reflect a relationship between DRD4 and decreased physical activity. Many adults with ADD exhibit excessive daytime sleepiness and difficulty initiating activity (Brown and McMullen, 2001), a state of low arousal that could contribute to decreased caloric expenditure and thus weight gain over time. This in itself might explain the link between ADD symptoms and increased body mass seen in this and prior studies. Another consideration is that the VNTR polymorphism under consideration is in linkage disequilibrium with an entirely different gene in the same chromosomal region, which itself affects the phenotype under investigation (Hanson and Knowler, 1998) and/or alters the expression of this VNTR.

A common limitation of genetic association studies looking at genotype/phenotype relationships is the potential for population stratification, which may lead to spurious positive results. Of particular importance to the current study is that significant variation in DRD4 VNTR allele frequencies among different populations has been reported 
(Chang et al, 1996). An optimal way to address this issue is the use of genomic controls (Devlin et al, 2001); however, we did not have sufficient funding to employ this method currently. Use of genomic controls in future work, and replication of our findings in independent samples, would thus be of great importance in confirming our initial results.

Notwithstanding these limitations, the current data point to a possible association between the 7R allele of DRD4 and both childhood inattention and dysphoria, as well as adult obesity, in overeating women with SAD. We speculate that the 7R allele of DRD4 may predispose young women to a series of behavioral problems over time reflecting central dopamine dysfunction. More work is needed to replicate and extend these findings and to examine these associations in other overeating and/or ADD populations.

\section{ACKNOWLEDGEMENTS}

A component of the current data was presented at the American College of Neuropsychopharmacology annual meeting, San Juan, Puerto Rico, December 2002. Project funding and personal funding for Dr Levitan were provided by the Ontario Mental Health Foundation and NARSAD. We thank Bronwyn Mackenzie for her help with database management.

\section{REFERENCES}

Altfas JR (2002). Prevalence of attention deficit/hyperactivity disorder among adults in obesity treatment. BMC Psychiatry 2: 9.

Arbisi PA, Depue RA, Krauss S, Spoont MR, Leon A, Ainsworth B et al (1994). Heat-loss response to a thermal challenge seasonal affective disorder. Psychiatry Res 52: 199-214.

Arias B, Gutierrez B, Pintor L, Gasto C, Fananas L (2001). Variability in the 5-HT(2A) receptor gene is associated with seasonal pattern in major depression. Mol Psychiatry 6: 239-242.

Asghari V, Sanyal S, Buchwaldt S, Paterson A, Jovanovic V, Van Tol HH (1995). Modulation of intracellular cyclic AMP levels by different human dopamine D4 receptor variants. J Neurochem 65: 1157-1165.

Baptista T (1999). Body weight gain induced by antipsychotic drugs: mechanisms and management. Acta Psychiatr Scand 100: 3-16.

Barr CL, Wigg KG, Bloom S, Schachar R, Tannock R, Roberts W et al (2000). Further evidence from haplotype analysis for linkage of the dopamine D4 receptor gene and attention-deficit hyperactivity disorder. Am J Med Genet 96: 262-267.

Blum K, Sheridan PJ, Wood RC, Braverman ER, Chen TJ, Comings DE (1995). Dopamine D2 receptor gene variants: association and linkage studies in impulsive-addictive-compulsive behaviour. Pharmacogenetics 5: 121-141.

Blundell JE, Cooling J (1999). High-fat and low-fat (behavioural) phenotypes: biology or environment? Proc Nutr Soc 58: 773-777.

Brown TE, McMullen Jr WJ (2001). Attention deficit disorders and sleep/arousal disturbance. Ann NY Acad Sci 931: 271-286.

Chang F-M, Kidd JR, Livak KJ, Pakstis AJ, Kidd KK (1996). The world-wide distribution of allele frequencies at the human dopamine D4 receptor locus. Hum Genet 98: 91-101.

Civelli O (1995). Molecular biology of the dopamine receptor subtypes. In: Bloom FE, Kupfer DJ (eds). Psychopharmacology the Fourth Generation of Progress. Raven Press: New York. pp $155-161$.

Clement K, Garner C, Hager J et al (1996). Indication for linkage of the human OB gene region with extreme obesity. Diabetes 45: 687-690.
Cohen RM, Gross M, Nordahl TE, Semple WE, Oren DA, Rosenthal N (1992). Preliminary data on the metabolic brain pattern of patients with winter seasonal affective disorder. Arch Gen Psychiatry 49: 545-552.

Comings DE, Blum K (2000). Reward deficiency syndrome: genetic aspects of behavioral disorders. Prog Brain Res 126: 325-341.

Comings DE, Gade R, MacMurray JP, Muhleman D, Peters WR (1996). Genetic variants of the human obesity (OB) gene: association with body mass index in young women, psychiatric symptoms, and interaction with the dopamine D2 receptor (DRD2) gene. Mol Psychiatry 1: 325-335.

Curran S, Mill J, Sham P, Rijsdijk F, Marusic K, Taylor E et al (2001). QTL association analysis of the DRD4 exon 3 VNTR polymorphism in a population sample of children screened with a parent rating scale for ADHD symptoms. Am J Med Genet 105: 387-393.

Depue RA, Arbisi P, Krauss S, Iacono WG, Leon A, Muir R et al (1990). Seasonal independence of low prolactin concentration and high spontaneous eye blink rates in unipolar and bipolar II seasonal affective disorder. Arch Gen Psychiatry 47: 356-364.

Devlin B, Roeder K, Wasserman L (2001). Genomic control, a new approach to genetic-based association studies. Theor Popul Biol 60: 155-166.

Enoch MA, Goldman D, Barnett R, Sher L, Mazzanti CM, Rosenthal NE (1999). Association between seasonal affective disorder and the 5-HT2A promoter polymorphism, -1438G/A. Mol Psychiatry 4: 89-92.

Evans KR, Vaccarino FJ (1990). Amphetamine- and morphineinduced feeding: evidence for involvement of reward mechanisms. Neurosci Biobehav Rev 14: 9-22.

Faraone SV, Biederman J, Weiffenbach B, Keith T, Chu MP, Weaver A et al (1999). Dopamine D4 gene 7-repeat allele and attention deficit hyperactivity disorder. Am J Psychiatry 156: 768-770.

Faraone SV, Doyle AE, Mick E, Biederman J (2001). Meta-analysis of the association between the 7-repeat allele of the dopamine $\mathrm{D}(4)$ receptor gene and attention deficit hyperactivity disorder. Am J Psychiatry 158: 1052-1057.

First MB, Spitzer RL, Williams JB, Gibbon M (2002). Structured Clinical Interview for DSM-IV-Patient Edition (SCID-P). American Psychiatric Press: Washington, DC. pp 337-348.

Fleming J, Levy L (2002). Eating disorders in women with AD/HD. In: Quinn PO, Nadeau KG (eds). Gender Issues and $A D / H D$ : Research, Diagnosis, and Treatment. Advantage Books: Silver Spring, MD. pp 411-426.

Halford JC (2001). Pharmacology of appetite suppression: implication for the treatment of obesity. Curr Drug Targets 2: 353-370.

Hanson RL, Knowler WC (1998). Analytic strategies to detect linkage to a common disorder with genetically determined age of onset: diabetes mellitus in Pima Indians. Genet Epidemiol 15: 299-315.

Hernandez L, Hoebel BG (1990). Feeding can enhance dopamine turnover in the prefrontal cortex. Brain Res Bull 25: 975-979.

Holmes J, Payton A, Barrett JH, Hever T, Fitzpatrick H, Trumper AL et al (2000). A family-based and case-control association study of the dopamine D4 receptor gene and dopamine transporter gene in attention deficit hyperactivity disorder. Mol Psychiatry 5: 523-530.

Hudziak JJ, Heath AC, Madden PF, Reich W, Bucholz KK, Slutske $\mathrm{W}$ et al (1998). Latent class and factor analysis of DSM-IV ADHD: a twin study of female adolescents. J Am Acad Child Adolesc Psychiatry 37: 848-857.

Johansson C, Smedh C, Partonen T, Pekkarinen P, Paunio T, Ekholm J (2001). Seasonal affective disorder and serotoninrelated polymorphisms. Neurobiol Dis 8: 351-357.

Johansson C, Willeit M, Smedh C, Ekholm J, Paunio T, Kieseppa T et al (2003). Circadian clock-related polymorphisms in seasonal 
affective disorder and their relevance to diurnal preference. Neuropsychopharmacology 28: 734-739.

Krauchi K, Reich S, Wirz-Justice A (1997). Eating style in seasonal affective disorder: who will gain weight in winter? Comp Psychiatry 38: 80-87.

Krauchi K, Wirz-Justice A, Graw P (1993). High intake of sweets late in the day predicts a rapid and persistent response to light therapy in winter depression. Psychiatry Res 46: 107-117.

LaHoste GJ, Swanson JM, Wigal SB, Glabe C, Wigal T, King N et al (1996). Dopamine D4 receptor gene polymorphism is associated with attention deficit hyperactivity disorder. Mol Psychiatry 1: 121-124.

Lam RW, Tam EM, Grewal A, Yatham LN (2001). Effects of alphamethyl-para-tyrosine-induced catecholamine depletion in patients with seasonal affective disorder in summer remission. Neuropsychopharmacology 25(Suppl): S97-101.

Lam RW, Zis AP, Grewal A, Delgado PL, Charney DS, Krystal JH (1996). Effects of rapid tryptophan depletion in patients with seasonal affective disorder in remission after light therapy. Arch Gen Psychiatry 53: 41-44.

Leshner AI, Koob GF (1999). Drugs of abuse and the brain. Proc Assoc Am Physicians 111: 99-108.

Levitan RD, Jain UR, Katzman MA (1999). Seasonal affective symptoms in adults with residual attention-deficit hyperactivity disorder. Comp Psychiatry 40: 261-267.

Levitan RD, Kaplan AS, Brown GM, Vaccarino FJ, Kennedy SH, Levitt AJ et al (1998). Hormonal and subjective responses to intravenous $m$-chlorophenylpiperazine in women with seasonal affective disorder. Arch Gen Psychiatry 55: 244-249.

Levy F, Hay DA, McStephen M, Wood C, Waldman I (1997). Attention-deficit hyperactivity disorder: a category or a continuum? Genetic analysis of a large-scale twin study. J Am Acad Child Adolesc Psychiatry 36: 737-744.

Li WD, Joo EJ, Furlong EB, Galvin M, Abel K, Bell CJ et al (2000). Melanocortin 3 receptor (MC3R) gene variants in extremely obese women. Int J Obes Relat Metab Disord 24: 206-210.

Lichter JB, Barr CL, Kennedy JL, Van Tol HH, Kidd KK, Livak KJ (1993). A Hypervariable segment in the human dopamine receptor D4 (DRD4) gene. Hum Mol Genet 2: 767-773.

Macdiarmid JI, Cade JE, Blundell JE (1996). High and low fat consumers, their macronutrient intake and body mass index: further analysis of the National Diet and Nutrition Survey of British Adults. Eur J Clin Nutr 50: 505-512.

Madden PA, Heath AC, Rosenthal NE, Martin NG (1996). Seasonal changes in mood and behavior. The role of genetic factors. Arch Gen Psychiatry 53: 47-55.

Martel P, Fantino M (1996). Mesolimbic dopaminergic system activity as a function of food reward: a microdialysis study. Pharmacol Biochem Behav 53: 221-226.

McCracken JT, Smalley SL, McGough JJ, Crawford L, Del'Homme M, Cantor RM et al (2000). Evidence for linkage of a tandem duplication polymorphism upstream of the dopamine D4 receptor gene (DRD4) with attention deficit hyperactivity disorder (ADHD). Mol Psychiatry 5: 531-536.

Meador-Woodruff JH, Damask SP, Wang J, Haroutunian V, Davis KL, Watson SJ (1996). Dopamine receptor mRNA expression in human striatum and neocortex. Neuropsychopharmacology 15: 17-29.

Mill J, Curran S, Kent L, Richards S, Gould A, Virdee V et al (2001). Attention deficit hyperactivity disorder (ADHD) and the dopamine D4 receptor gene: evidence of association but no linkage in a UK sample. Mol Psychiatry 6: 440-444.

Mrzljak L, Bergson C, Pappy M, Huff R, Levenson R, GoldmanRakic PS (1996). Localization of dopamine D4 receptors in GABAergic neurons of the primate brain. Nature 381: 245-248.

Muglia P, Jain U, Macciardi F, Kennedy JL (2000). Adult attention deficit hyperactivity disorder and the dopamine D4 receptor gene. Am J Med Genet 96: 273-277.
Neumeister A, Willeit M, Praschak-Rieder N, Asenbaum S, Stastny $\mathrm{J}$, Hilger $\mathrm{E}$ et al (2001). Dopamine transporter availability in symptomatic depressed patients with seasonal affective disorder and healthy controls. Psychol Med 31: 1467-1473.

Noble EP (2003). D2 dopamine receptor gene in psychiatric and neurologic disorders and its phenotypes. Am J Med Genet 116(Suppl): 103-125.

Ozaki N, Rosenthal NE, Pesonen U, Lappalainen J, Feldman-Naim S, Schwartz PJ et al (1996). Two naturally occurring amino acid substitutions of the 5-HT2A receptor: similar prevalence in patients with seasonal affective disorder and controls. Biol Psychiatry 40: 1267-1272.

Praschak-Rieder N, Willeit M, Winkler D et al (2002). Role of family history and 5-HTTLPR polymorphism in female seasonal affective disorder patients with and without premenstrual dysphoric disorder. Eur Neuropsychopharmacol 12: $129-134$

Rosenthal NE (1995). Syndrome triad in children and adolescents. Am J Psychiatry 152: 1402.

Rosenthal NE, Genhart M, Jacobsen FM, Skwerer RG, Wehr TA (1987). Disturbances of appetite and weight regulation in seasonal affective disorder. Ann NY Acad Sci 499: 216-230.

Rosenthal NE, Mazzanti CM, Barnett RL, Hardin TA, Turner EH, Lam GK et al (1998). Role of serotonin transporter promoter repeat length polymorphism (5-HTTLPR) in seasonality and seasonal affective disorder. Mol Psychiatry 3: $175-177$.

Rosenthal NE, Sack DA, Gillin JC, Lewy AJ, Goodwin FK, Davenport $\mathrm{Y}$ et al (1984). Seasonal affective disorder. A description of the syndrome and preliminary findings with light therapy. Arch Gen Psychiatry 41: 72-80.

Rowe DC, Stever C, Chase D, Sherman S, Abramowitz A, Waldman ID (2001). Two dopamine genes related to reports of childhood retrospective inattention and conduct disorder symptoms. $\mathrm{Mol}$ Psychiatry 6: 429-433.

Rowe DC, Stever C, Giedinghagen LN, Gard JM, Cleveland HH, Terris ST (1998). Dopamine DRD4 receptor polymorphism and attention deficit hyperactivity disorder. Mol Psychiatry 3: 419-426.

Schwartz PJ, Murphy DL, Wehr TA, Garcia-Borreguero D, Oren DA, Moul DE et al (1997). Effects of meta-chlorophenylpiperazine infusions in patients with seasonal affective disorder and healthy control subjects. Diurnal responses and nocturnal regulatory mechanisms. Arch Gen Psychiatry 54: 375-385.

Seeman P, Van Tol HH (1994). Dopamine receptor pharmacology. Trends Pharmacol Sci 15: 264-270.

Sher L (2001). Genetic studies of seasonal affective disorder and seasonality. Comp Psychiatry 42: 105-110.

Sherman DK, Iacono WG, McGue MK (1997). Attention-deficit hyperactivity disorder dimensions: a twin study of inattention and impulsivity-hyperactivity. $\mathrm{J} A m$ Acad Child Adolesc Psychiatry 36: 745-753.

Smalley SL, Bailey JN, Palmer CG, Cantwell DP, McGough JJ, Del'Homme MA et al (1998). Evidence that the dopamine D4 receptor is a susceptibility gene in attention deficit hyperactivity disorder. Mol Psychiatry 3: 427-430.

Stein MA, Sandoval R, Szumowski E, Roizen N, Reinecke MA, Blondis TA et al (1995). Psychometric characteristics of the Wender Utah Rating Scale (WURS): reliability and factor structure for men and women. Psychopharmacol Bull 31: 425-433.

Swanson JM, Sunohara GA, Kennedy JL, Regino R, Fineberg E, Wigal T et al (1998). Association of the dopamine receptor D4 (DRD4) gene with a refined phenotype of attention deficit hyperactivity disorder (ADHD): a family-based approach. $\mathrm{Mol}$ Psychiatry 3: 38-41.

Tahir E, Yazgan Y, Cirakoglu B, Ozbay F, Waldman I, Asherson PJ (2000). Association and linkage of DRD4 and DRD5 with 
attention deficit hyperactivity disorder (ADHD) in a sample of Turkish children. Mol Psychiatry 5: 396-404.

Theisen FM, Linden A, Konig IR, Martin M, Remschmidt H, Hebebrand J (2003). Spectrum of binge eating symptomatology in patients treated with clozapine and olanzapine. J Neural Transm 110: 111-121.

Todd RD, Neuman RJ, Lobos EA, Jong YJ, Reich W, Heath AC (2001). Lack of association of dopamine D4 receptor gene polymorphisms with ADHD subtypes in a population sample of twins. Am J Med Genet 105: 432-438.

Van Tol HH, Wu CM, Guan HC, Ohara K, Bunzow JR, Civelli O et al (1992). Multiple dopamine D4 receptor variants in the human population. Nature 358: 149-152.
Wang GJ, Volkow ND, Logan J, Pappas NR, Wong CT, Zhu W et al (2001). Brain dopamine and obesity. Lancet 357: 354-357.

Ward MF, Wender PH, Reimherr FW (1993). The Wender Utah Rating Scale: an aid in the retrospective diagnosis of childhood attention deficit hyperactivity disorder. Am J Psychiatry 150: 885-890.

Williams JBW, Link MJ, Rosenthal NE, Terman M (1988). Structured Interview Guide for the Hamilton Depression Rating Scale-Seasonal Affective Disorder Version (SIGH-SAD). New York State Psychiatric Institute: New York, NY.

Zametkin AJ, Nordahl TE, Gross M, King AC, Semple WE, Rumsey $\mathrm{J}$ et al (1990). Cerebral glucose metabolism in adults with hyperactivity of childhood onset. $N$ Engl J Med 323: 1361-1366. 